\title{
Development Method for Shariah Compliant e-Commerce Payment Processing
}

\author{
Tamrin Amboala, Ainnur Hafizah Anuar Mokhtar, Mohd Zulkifli Muhammad, Mohamad Fauzan bin \\ Noordin, and Roslina Othman
}

\begin{abstract}
The article is a response to rapid uptake of online transactions that encompasses the secure transactions that comply with the Shariah principles. The algorithm in the articles proposed the inclusion of Intermediate Shariah Transaction Party (ISTP) as an intermediary for communications between merchant and customers before the transactions can be concluded. The design facilitates the efficient and effective e-commerce transaction process to alleviate three common shortcomings in e-commerce transactions namely riba', gharar and the validity and the legality of e-commerce transactions from Shariah point of view without compromising the security aspects of the transactions. The designs were refined and presented before by the Islamic scholars before the final design was agreed on. This invention will become a major breakthrough in Shariah compliance ecommerce transactions in order to serve 2.1 billion Muslims Ummah worldwide.
\end{abstract}

Index Terms-Client, gharar, intermediate Shariah transaction party, merchant, riba', Shariah compliant.

\section{INTRODUCTION}

Trade and commerce have always been part of business ethics and legal system (Shariah) in Islam. The convergence of IT and commerce have brought more complex levels of Islamic business and commerce ethics that require the Islamic jurisprudents to expand their tools of evaluation and analysis beyond the traditional context. With a comprehensive approach taking into account as regulations and the existing technological tools brought into Shariah's model, this article seeks and develops an understanding how to provide alternative solution to the conventional and unIslamic e-commerce transaction.

Payment processing method or electronic payment system is important in e-commerce transaction or online transaction. According to Sumanjeet broadly electronic payment systems can be classified into four categories: Online Credit Card Payment System, Online Electronic Cash System, Electronic Cheque System and Smart Cards based Electronic Payment System. It depends on the buyer

Manuscript received June 12, 2014; revised August 10, 2014.

Tamrin Amboala and Ainnur Hafizah Anuar Mokhtar are with the Labuan School of Informatics Science, University Malaysia Sabah Labuan International Campus, Federal Territory of Labuan, Malaysia (e-mail: ramdzan_trn@yahoo.com, ain_146@hotmail.com).

Mohd Zulkifli Muhammad is with the Faculty of Entrepreneurship \& Business, Universiti Malaysia Kelantan, Kelantan, Malaysia (e-mail: zulrider@yahoo.com).

Mohamad Fauzan bin Noordin and Roslina Othman are with Kuliyyah of Information \& Communication Technology, International Islamic University Malaysia, Selangor, Malaysia (e-mail: fauzan@iium.edu.my, roslina@iium.edu.my). on how they want to make the payment [1].

There are several main challenges of on-line transaction from Shariah perspective which will be discussed hereafter which are related to payment processing method and some issues happen during the payment process. Addressing these aspects require Islamic jurist and scholars to scrutinize both the technical aspects of the on-line transaction and the legal aspects in terms of Shariah.

Islam accords the importance to the trading sector as source of wealth and the role it plays for the development of the country and the Ummah (Muslim nation) as a whole. In this regard, the holy Quran abounds with many references about trade and commercial activities [2]. The Quranic verses support this statement as below:

"O you who believe! Eat not up your property among yourselves unjustly except it is a trade amongst you, by mutual consent. And do not kill yourselves (nor kill one another). Surely, Allah is Most Merciful to you' (4:29).

"Woe to Al-Mutaffifin [those who give less measure and weight (decrease the rights of others)]" (83:1).

"O man of faith! Do not devour the goods of another with injustice but trade based on mutual agreement and good-will is allowed" (4:29).

"O ye who believe; devour not usury, doubled and multiplied; but fear Allah, that ye may prosper" (3:130).

In the following section the article presents several issues pertaining to on-line transaction in e-commerce namely gharar, riba and the legality of the contract that binds transactions from the Shariah point of view.

Considering the complexity in the way business and commerce are being carried out, the transaction of today is very necessary to create an entirely new model and methods for a modern Islamic transaction for the Ummah. By combining several methods such as Information technological approach, e-commerce infrastructure, regulatory framework, with some adjustment and modification in order to fit the Shariah's principles is deemed necessary.

\section{LITERATURE SURVEY}

\section{A. E-Commerce Transaction or Online Transaction}

In order to secure transaction online, it must fulfil two main requirements. The first is concerning how to protect data from the unauthorized parties (confidentiality) and how to guarantee the integrity of the transaction itself. Confidentiality ensures that the data travels on-line only be received and access by the authorized party(s).

Confidentiality sometimes is associated with secrecy and 
privacy. On the other hand, Trusted Network Interpretation defines that the integrity ensures that computerized data are the same as those in source documents; they have not been exposed to accidental or malicious alteration or destruction [3].

In order to guarantee the integrity in the context of communication on line, Stalling suggested that the data sent must ensure the following [4]:

1) The data must be protected against content modification - it includes changes to the contents of a message, including insertion, deletion, transposition and modification.

2) The data must be protected against timing modification - delay or replay messages.

3) Source repudiation - denial of transmission of message by source.

4) Destination repudiation - denial of receipt of message by destination.

If man-in-the-middle is able to intercept the message sent to a merchant, he might not just modify the message (i.e. the order quantity), yet able to replay the same message to repurchase the product several times.

There is a patent by Rabindranath Dutta which is entitled "Third Party contract Depository for e-commerce Transactions". The patent was filed in 2000 and awarded in 2008. From this patent it relates to a method, system and program for ensuring the authenticity of electronic documents generated during e-commerce transactions. From this patent, the method, means and program function include : 1) creating an electronic depository for storing electronic documents generated during an e-commerce transactions, 2) enabling an automatic receipt at the electronic depository of an electronic document created during an e-commerce transaction; 3) storing the electronic documents in the electronic depository; (4) providing each party to the transaction With a document ID for later access to the electronic document; and (5) allowing later read-only access to the electronic document and preventing any modifications to the document once it has been stored [5].

According to this patent, most e-commerce transactions are bipartite and occur between a merchant and a buyer. The merchant is represented online by a Web site located on a Web server and accessible via a universal resource locator (URL) or Web address. The buyer connects to the Internet via one of several known means of connecting to the Internet and accesses the merchant's Web site. The merchant and the buyer enter into a transaction Within the Web server, which is recorded in electronic form on the Web server as an agreement (or contract). Thus, the contract is typically stored in the Web server of the merchant. A buyer may be provided with the opportunity to print the contract prior to terminating the connection to the Web site.

E-commerce transactions may be either point-topoint/bipartite (i.e., an individual communicating directly with another individual or a business Web site) or multipoint (i.e., many individuals transacting with each other, as in a swap room, or with on-line auctions, for example). Typically, a Web server provides the background within which these e-commerce transactions take place.

The invention by Rabindranath Dutta contributes to the integrity of the transaction data by providing the depository of the electronic documents especially the contract documents between the transaction parties on line. The contract documents are significantly more important in business-to-business than the other e-commerce model.

Liu, Y., Muller highlights in the Static ComplianceChecking Framework For Business Process Model the importance of various growing number of regulatory requirements imposed on business process [6]. Thus, this framework model deploy a model-checking technology in order to verified the process againts the compliance rules. In the United States itself the formulation of the SarbanesOxley Act reguire the the businesses and corporates to conform with such regulation in order to prevent further of coporate fraud [7].

Governatori, G., also highlights the large number of regulatory obligations the process may or comply with. Nowadays the new challenge arises for businesses to comply with these regulations and become most critical objective in their emerging business process platforms. Further in order to providing tools and technique to evaluate the compliance degree of a given process this article suggest and devise a diagnostic framework to assess the compliance gaps present in a given process through Semantic Annotations [8].

Those regulations imposed as a consequence and reactive in nature which later is adjusted by the corporates as the de jure standards. In Shariah based e-commerce transactions however the Muslims believe that the code of ethics that encompasses the day-to-day activities particularly in business is pre-defined by the divine law. This article suggests the inclusion of the so called Intermediate Shariah Transaction Party (ISTP) which will serve as the intermediary third party to provide evidence between the customer and merchant.

This paper suggests the intermediary third party approach as a technological solution and means for the requirements derives from the Shariah perspective whilst maintaining and incorporating the conventional security requirements as stated earlier by Stallings.

\section{B. E-Commerce Business Model and Business Process}

E-commerce is a kind of business-related activities which are concerned with consumers, manufacturers, service providers and intermediaries with the help of computer network. Moreover, e-commerce enables potentially billions of consumers and businesses worldwide to be engaged in business activities. This set of dynamic technology, application, and business process connecting numerous enterprises, customers and specific communities through electronic transactions where trade of goods and information transfer are done electronically [9].

According to Ainnur Hafizah, Tamrin Amboala, Mohd Zulkifli \& Mohd Sarwar E-Alam, it can be concluded that ecommerce transaction is a commercial transaction through electronic media which also covers all commercial transactions through electronic media such as facsimile, telex, Electronic Data Interchange and telephone [10].

E-commerce system will go through some of the activity which is called business process. The business processes require the merchants or organizations to have websites in which they provide necessary information including the 
profile of the company, product or service being offered. The consumer side as a prospective buyer, the internet provides a wide and free access to all the companies registered with the virtual world. Information exchange in this arena occurs in one way or interactively.

Business process in e-commerce involves collection of activities designed to produce a specific output for a particular customer or market that makes use internet infrastructures. It implies a strong emphasis on how the work is done within and organization, in contrast to a product's focus on what. A process is thus a specific ordering of work activities across time and place, with a beginning, an end, and clearly defined inputs and outputs: a structure for action [11].

The first business process in e-commerce is called information sharing. In this process, the seller will try to find out as much buyer as they can while the buyer make efforts to get information about the products or services that they want and find out how other people percept on the products or services. After the process of information sharing being done, the next business process is ordering products or services electronically. Two interacting parties must perform certain activities until the purchase agreement can be done legally and correctly.

All the processes are carried out via internet infrastructure can be categorized based on four flows of entities that should be done clearly which are:

1) Flow of goods and services (digital and non-digital products)

2) Flow of information (product details and description)

3) Flow and mode of payment (credit card, debit card and etc.)

4) Flow of documents (quotation, invoice and etc.)

E-commerce facilities available should be synchronized with these four flows until the transactions can be done in an efficient, effective, secure and well-controlled manner.

Since e-commerce has becoming popular as more people are becoming accustomed to purchasing products online via the Internet. Such purchases can be facilitated through the use of a third-party, online payment service, such as the PayPal ${ }^{\circledR}$ online payment service, provided by PayPal ${ }^{\circledR}$ of San Jose, California. As stated in a patent document entitled "Method and System for Facilitating Merchant-Initiated Online Payments" the problem with existing online payment services is that the customer must navigate away from the merchant's Website to make a payment. For example, the customer must login to the payment service provider's Website for each online payment the customer makes. The extra time spent logging into and navigating the payment service provider's Website to make a payment is inconvenient, particularly when the purchase involves a small amount of money [12].

The patent was filed in 2004 and awarded in 2012. This patent relates to a method and system for facilitating merchant-initiated online payments is disclosed. According to one aspect of the present invention, a payment service provider's server receives a user's request, via a merchant's server, to establish a merchant-initiated payment relationship or agreement.

Accordingly, the payment service provider presents the user with options to customize the terms of the merchant- initiated payment agreement. After the agreement has been established and the terms customized, the merchant server communicates a merchant-initiated payment request to the pavement service provider for a transaction entered into with the user. The payment service provider's server processes the payment request after verifying that processing the payment does not exceed the user-customized terms of the agreement.

Furthermore the client-merchant communication must be in place before a contract that bounds the transaction and sealed by both parties. The existence of Intermediate Transaction Party in the above invention ensures that communication are guaranteed and secured by providing communication platform for client-merchant communication and transactions that include user-customized terms in the contract formation.

The above invention provides a comprehensive application model and reference for payment processing method base on Shariah principles as it provide mutual communication between merchant and clients; a prior requirements in before the transactions are regarded valid or lawful from Shariah's perspective. The payment processing method for secure Shariah compliant e-commerce adopt and incorporate almost similar processes before customizing the communication, transactions and contract formation that based on Shariah principles.

\section{Methodology}

As stated by Giaglis and Doukidis who examined the nature of business processes in the light of modern change management approaches and propose a set of requirements for their modeling are as follows:

1) Technical requirements: Formal modelling, quantitative modelling, stochastic modelling, model documentation, model adaptability/reusability and objective-driven modelling.

2) Political/social requirements: Feasibility of alternative designs, communication of models and user friendliness.

Technical requirements can be regarded as micro development whilst political/social requirements are the macro requirements and it must be obtained prior any effort and resources are allocated into the development. This approach is sometimes referred to as socio-technical approach to software development.

This article places the second requirements before the first one in order to grasp understanding on how to apply the processing method in the e-commerce context. These requirements in this context are issues surrounding the ecommerce from Shariah perspective such as riba (usury) and uncertainty and anonymity (gharar). This includes regulatory issues if the payment processing method were to be implemented in real e-commerce application.

Action research methodology is chosen in this development method due to its systematic cyclical method of planning, taking action, observation and evaluation and critical reflection prior to planning the next phase [11]. The research goals have been set to identify the research issues namely gharar (fraud) and riba' (usuary). 
Literally riba means an increase or increase. According to Islamic Jurist it can be defined as usury or a practice of lending money with interest rates. In this concern, Islamic Fiqh Assembly issued its decision No. 108 (12/2) stated [13]:

1) It is not permitted to issue uncovered credit cards or to deal in them if there is a condition that fixes usurious increase even if a user intends to pay up within a given free period.

2) It is permitted to issue uncovered credit cards as long as there is no condition that fixes usurious increases to be added to debt. Here are two (2) sub points:

a) It is lawful (for the bank or issuer) to receive a fixed charge for the issue or renewal of such cards as a wage for service rendered.

b) It is also lawful to receive commission from the trader for purchase, by the customer provided that selling by card is equal in price to selling in cash.

However, how does Islam accept the concept of credit card as a medium of on-line payment? What are the underlying principles required by Shariah in the functionality of credit card?

Literally gharar means fraud and has often been associated with risk and uncertainty from Shariah point of view. In order to avoid from gharar both parties; buyers and sellers are required to have adequate information of values they intend to exchange, the existence of the object (product or service), obtainable, its quantity, quality and attributes are identified and it can duly be delivered [14].

The anonymity of Internet users including traders contribute to the complexity of defining gharar in its new dimension and challenge. It used to happen in which the subject matter is concealed from the buyer without he or she knowing exactly its future result. In the sense of ecommerce transactions there are also three major concerns pertaining to gharar; the uncertainties over the products or the services itself, uncertainties over pricing and delivery and deferment [14].

Those above underlying issues require collaborative method in action research that include all relevent parties in e-commerce transaction comprising observation, participation and informal forum to throw the new ideas and implementation action for change. Action research is a way to increase understanding of how change in one's actions or practices can mutually benefit a community of practiotioners which is the e-commerce stakeholders in this case.

\section{A. Focus Group}

The empirical research adopted for this study is one of a qualitative, semi-structured interview methodology. This method is chosen to engineer the requirements of the Shariah principles in e-commerce. The interview questions are drawn up for different stakeholders in different component model such as;

1) Islamic scholars and academia to illuminate and refine the surrounding issues of on line transaction.

2) E-commerce stakeholders from the industry that deals with e-commerce transaction in its real context.

The team members attempt to illuminate the multiple approaches for the implementation of Shariah principle in ecommerce transaction derived from open ended responses from the focus group.

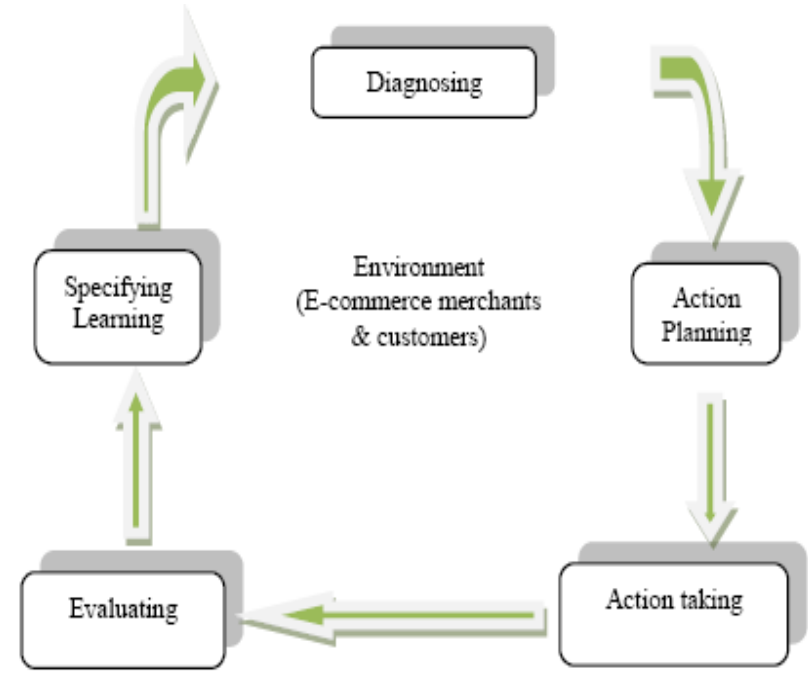

Fig. 1. The action research cycle.

The process of the action research method works iteratively around the environment of e-commerce itself. Understanding how e-commerce transaction processes and information flows work around merchants, customers, banking and financial institution will provide the researchers the holistic schematic view of the entire e-commerce environment.

In order to address the surrounding issues in e-commerce above the researchers adapt the action research as illustrated in Fig. 1. The action research is chosen due to its nature that encourage active participation among the practitioners [15]. The practitioners in this case are merchants and customers a part from the development team.

The key aspect of the e-commerce infrastructure is the collaborative nature of the undertaking. This provides a practical research scope and boundaries of the research domain. The researchers work closely with the e-commerce stakeholders and practitioners located within the environment to obtain necessary insight to understand the anomalies being studied [16].

The peculiar anomalies in this context are issues of Shariah compliance principle in e-commerce transaction itself which led to issues on gharar and riba. Diagnosing corresponds to the identification of the primary issues in ecommerce trading from Islam point of view. The diagnosis develops the insight and understandings about the nature of complex organization and its problem.

Researchers and e-commerce stakeholders then start an engagement to collaborate in the next activity, action planning. A part from the e-commerce stakeholders (merchants, traders and etc.) the researchers will also seek collaboration with other parties such as representative from the legal provision. This specifies organizational actions that should relieve or improve these primary problems. The discovery of the planned actions is guided by the action research cycle.

The action-taking phase then implements the planned action. The researchers and practitioners alike then implement the active intervention into the identified issues, causing certain changes to be made. Several forms of intervention strategy can be adopted. For instance, the 
intervention might be sought directly or indirectly from the experiences gathered during and after the implementation and translation of the proposed algorithm in the communications and e-commerce transactions.

After the actions are completed, the collaborative researchers and practitioners undertake the evaluating of the outcomes. This will include a determination of whether the proposed model effects of the action are materialized and will alleviate the problems and issues in e-commerce trading.

Once change is successful, the evaluation must critically scrutinize whether the undertaken action has direct impact on its consequence or may because some other elements which have not been addressed previously. If the changes are unsuccessful, the additional knowledge may provide foundations for diagnosing in preparation for further action research intervention.

Finally, the results of this development will present important new knowledge to the scientific community faced in the future research particularly related to online trading from Islamic perspective.

\section{B. Implementation and Experimental Approach}

This approach meets the Giaglis and Doukidis approach stated earlier which gathering set of micro requirements after gathering and deducting the fulfilling the first one (macro requirements). The researchers will implement the algorithm beyond and expand its laboratory experimental research in its limited sense and aim to isolate cause and effect by manipulation of what is thought to be the casual, or independent, variable and measurement of its effect on the dependent variable(s).

In this regard the laboratory experimental algorithm will also be tested and implemented in the real context. An internship IT consulting company works collaboratively with the academia as the solution provider for the technological means for Shariah based solution for ecommerce is appointed for the implementation in its industrial setting. The collaborative engagement is important in order to emphasis its usability by gaining the first-hand experience in its implementation.

As stated in the literature review basically there are four types of flow that involve throughout the e-commerce trading that must be regulated or at least managed accordingly by the communicating parties. The communicating parties involved are merchants, customers, intermediaries such as card issuer, acquirer and etc.

1) Flow of information

2) Flow of documents

3) Flow of money

4) Flow of goods

The proposed invention defines three main communicating parties involved. Firstly, the merchant who propose (offer) their product (service) or contract to the customers (second party) who later accept it and make a payment via online.

The third one is the Intermediate Shariah Transaction Party (ISTP). The ISTP functions as the trusted third party who ensures that the transactions data must be is not tampered according to the above requirements. ISTP will also ensure that payment is carried out using Shariah compliance card (credit or debit card) at the moment the customers initiating the payment to avoid riba.

Furthermore the ISTP provide a mechanism to validate the order by matching the information from the merchant's transaction data and the data presented by the customers to eliminate gharar associated to the uncertainty over the product details (quantity, pricing and delivery).

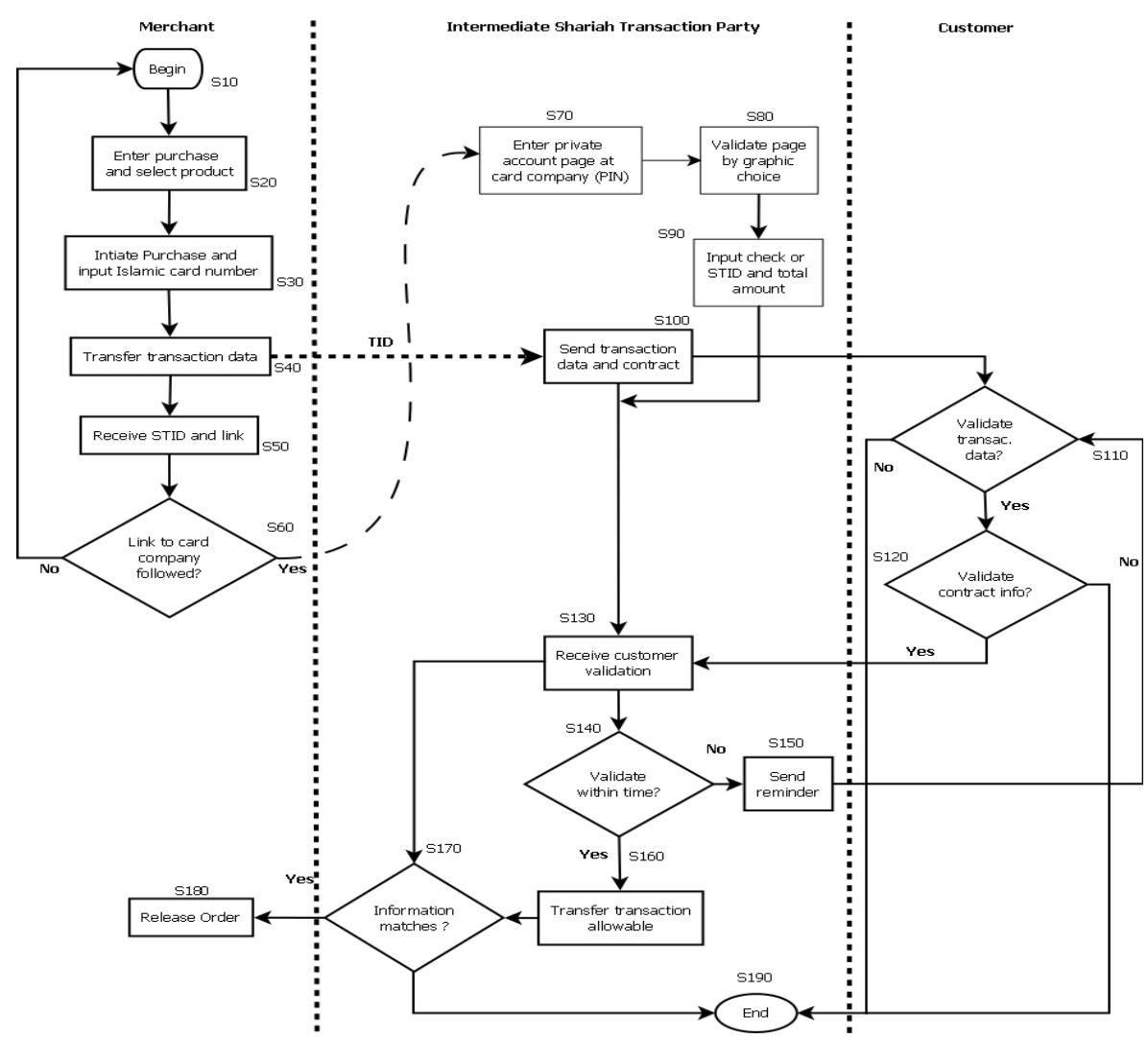

Fig. 2. Shariah compliant e-commerce transactions algorithm. 
In addition ISTP provides a platform for two communicating parties to (merchant and customer) to settle the agreement pertaining to products (services) before the card issuer and acquirer release the payment and the goods are delivered.

The proposed inventions and solution concern with the first two; flow of information and flow of documents. In other words the first two flows are more crucial and must be carried out and accomplished first. These processes must proceed before the last two processes (payment and product delivery).

The Internet has proved as an effective channel for marketing both products and service. However, it is believed that a part from the complexity of the computerized environment, the absence of a standard platform for the Muslims consumers that serve as an overall dominating practice and method that is based on Shariah principles has contributed further the slow e-commerce uptake.

This platform seeks solutions for a direct and instantaneous real time (and non-real time) communications between merchant and consumers. By having this invention both Muslim and non-Muslim consumers are believed to have more confidence and economically will benefit the merchants through the increase online sales.

As illustrated in the Fig. 2 the processing parts of the merchants are found in the left side of the diagram separated by the dotted lines whereas the main processing for customer validation to eliminate the gharar is managed by the ISTP are found and the middle. The right side is the customer processing part to validate both transaction data and contract information which further will be returned to ISTP information matches before the order releases.

The researchers translated the communication process between merchant-ISTP-customer in a flow chart in order to capture the entire business process. The workflow flow chart is chosen due to its capability to capture both the series and parallel processes and presented effectively [17]. Furthermore it draws the scope of the entire processes, which is the communication and business process in this case.

This invention meant to alleviate three common shortcomings (validity of the transactions, legality of the contract, gharar and riba) pertaining to conventional ecommerce transaction whilst utilizing the state-of the art encryption technology. This is accomplished by the processing method for secure value transaction and communication among merchant, ISTP and customer.

1) The customer enters a merchant's web-site and initiates order. The order generates among other data a unique transaction identification number (TID) when the customer completes the order sequence. (S10-S30)

2) The merchant transfer information to the Intermediate Shariah Transaction Party (ISTP). The merchant transfer a fraction of the standard information from a Shariah compliance card order and the transaction identity number (TID) to the ISTP. This transferred standard information could be possibly being encrypted form using state of the art encryption technologies. This information may be transferred by e-commerce website, any earlier established systems a proprietary network or by using e-mail. This transaction also includes a random number for verification of the transaction validation.
This method does not necessarily require communicating parties (merchant, ISTP and customer) to engage in real time communication by means of intermediary between merchant and customer and validation based on the time limit.

3) The merchant directs the customer to the ISTP. The merchant presents the customer with a link from the order confirmation page to the customer's personal account page at the ISTP. The merchant presents the customer with a link from the order confirmation page to the customer's personal account page at the ISTP. It is to be noted that the presented link could point directly to the customer's personal account page by using the credit or debit card number, a combination of information available from the credit or debit card, or any other account number, as part of the address in order to eliminate the need to introduce cookies in the order confirmation sequence in case a direct link is presented (S60).

4) The ISTP filter the product to detect initial halal status based on product category (liquor, pork and etc.). These steps can be carried out by means of but not limited to reference no. or automatic code generations to verify the halal status (S70-S80).

5) The customer validates the order to the ISTP (S130). These steps are meant to eliminate the gharar transaction which is always associated with fraud, risk and uncertainty. The steps require the ISTP to communicate with the customer to validate the transaction data (company name, product or services, pricing and delivery). Preferably these transaction data or ordered items are encrypted to maintain the confidentiality. Initially, the customer follows the link to, or is redirected to, the order confirmation on the personal account page presented by the ISTP.

In addition to the customer transaction validation above the embodiment also requires the customer to validate the contract from the merchant to the ISTP (S130-S140).

There is a possibility in this embodiment that the customer leave the order confirmation pass without following the link to the personal account page at the ISTP. This may allow the user to delay the confirmation to a more convenient moment before making decision.

However the confirmation must be done within a timelimit set by the ISTP (recommended maximum 3 days). The fourth step is followed by the ISTP presenting a personal and PIN code-protected page where the customer logs in to fill out a form. The page is identified by the customer as the real page transmitted from the ISTP by an earlier established identification to avoid computer generated strings. When the order has reached the ISTP, the customer is presented with the transaction data (company name, product or services, pricing and delivery) the customer must have an option to accept or reject the order (S90-S170).

In case there is a delayed, slow connection or for any other technical reason, the customer is offered to accept a pending order by typing a simple transaction identification number (STID) and total cost without revealing information about the ordered items (S110).

6) The ISTP confirms the order from the merchant via previously established channel that the customer has 
accepted the order and contract information validation. Once all the information matches (S190) only then the ISTP direct the merchant to release the order and accomplish the transaction (S210).

This algorithm is developed to enable the communications between all parties, merchant-ISTP-client compatible with the existing and future state of the art technology. These include Secure Electronic Transaction (SET), encryption technology, SSL/TLS. For example, in (S60) whenever the merchant presents the customer with the link from the order confirmation page to the customer's personal account page at the ISTP, the communications will be encrypted with SET or any kind of future secured channel communication.

The similar processes include in S40 and S100 which involve transaction data and contract whenever the parties communicate until the order releases in S180. However it's beyond the scope of this research to cover the discussion of the encryption technology.

\section{CONCLUSION}

This article presented the comprehensive payment processing method for Shariah compliant e-commerce transaction. The compliant is inferred based on qualitative method and approach that later transformed into processing method algorithm which is experimental in nature. The algorithm is suitable for each type business-to-consumer, business-to-business and consumer-to-consumer business model. The main drawback of this algorithm is that they are very lengthy and large to read in its step of process.

However in order to translate the algorithm into a real ecommerce applications additional two or more windows compared to the conventional e-commerce application to accommodate dialogue especially at customer-side process are needed. Some processes should be encapsulated such as validate transaction data and validate contract info (S110 and S120) in order to offset the lengthy and complex processes.

Neither the entire communication process between merchant-ISTP-customer suggest totally a new web based technology in e-commerce nor depend on the specific technology. In fact the researchers are revamping the ecommerce process in order to fulfill the Shariah requirements. The rest of the flows in e-commerce such as the flow of goods and payment are still applicable as in the conventional e-commerce.

The merchant-ISTP-customer processing is generic and do not specifically dependent on specific web technology. This will give an advantage for the processing steps to adopt any cutting edge technology in the future.

The algorithm has completed the diagnosing stage in the cycle of the stated action research [18]. The future research should be a repetition of the cycle of the action planning stage after diagnosing its implementation issues as depicted in Fig. 1. Another approach such as model simulation based on its application drawn from the understanding the behavior of the process or evaluating various aspects for learning purposes. Future research will identify every input gathered in this cycle to be diagnosed for further improvement.
Many works that explain role activity diagrams for process-based in information systems development through model simulations. Another example presented by including Fernández-Gutiérrez, Fabiola that provides practical case in health care systems through modeling and simulations. This work attempts to apply state-of-the-art industrial modeling and simulation tools in order to optimized workflow, equipment, and staff allocation for more efficient, effective, and economic image-guided therapy [19]. The method of modeling and simulations of processes may also be applicable to e-commerce processing method. Future research may embark on this method to see any significant results compared to the present method.

\section{REFERENCES}

[1] S. Sumanjeet, "Emergence of payment systems in the age of electronic commerce: The state of art," in Proc. First Asian Himalayas International Conference on Internet, 2009, pp. 1-18.

[2] M. Z. Muhammad, T. Amboala, and Z. Hassan, "Comprehensive approach for sharia' compliant e-commerce transaction," Journal of Internet Banking \& Commerce, vol. 16, no. 1, 2011.

[3] D. M. Abrams and M. V. Joyce, "Trusted system concepts," Computers \& Security, vol. 14, no. 1, pp. 45-56, 1995.

[4] W. Stallings, Cryptography and Network Security, 4/E. Pearson Education India, 2006.

[5] D. Rabindranath, "Third party contract depository for e-commerce transactions," U.S. Patent 7,437,310, October 14, 2008.

[6] L. Ying, S. Muller, and K. Xu, "A static compliance-checking framework for business process models," IBM Systems Journal, vol. 46, no. 2, pp. 335-361, 2007.

[7] T. Gray, "Canadian response to the US Sarbanes-Oxley Act of 2002: new directions for corporate governance," Parliamentary Information and Research Service, Library of Parliament, 2005.

[8] G. Guido, J. Hoffmann, S. Sadiq, and I. Weber, "Detecting regulatory compliance for business process models through semantic annotations," in Proc. Business Process Management Workshops, Springer Berlin Heidelberg, 2009, pp. 5-17

[9] P. Yewsiang, K.-U. Zaman, and M. Talha, "E-commerce today and tomorrow: A truly generalized and active framework for the definition of electronic commerce," in Proc. the 8th International Conference on Electronic Commerce: The new e-Commerce: Innovations for Conquering Current Barriers, Obstacles and Limitations to Conducting Successful Business on the Internet, 2006, pp. 553-557.

[10] A. H. A. Mokhtar, T. Amboala, M. Z. Muhammad, and M. S. EAlam, "Bai as-salam and e-commerce: A comparative analysis from Shariah perspectives," in Proc. the 2nd Applied International Business Conference, 2013, vol. 7, p. 8.

[11] R. Claude, A. Saint, B. Tiberghien, P. Agopian, P.-L. Catherine, and V. Soulleihet, "Process Modeling and Public Value: Performance Measurement for Emergency Assistance Services?" International Business Research, vol. 6, no. 2, 2013.

[12] O. Hugo, F. Chastagnol, Y.-L. Su, W. William, C. Brown, T. Dang, T. Veino, C. Gunby, C. Peter, and C. Steve, "Method and system for facilitating merchant-initiated online payments," U.S. Patent 8,175,938, May 8, 2012.

[13] M. Kazi. (2002). Malaysian banks launches first Islamic credit card in Asia. [Online]. Available: http://www.islamonline.net/English/news/2002-07/25/articles06.shtml

[14] M. Z. Muhammad, T. Amboala, and Z. Hassan, "Comprehensive approach for sharia' compliant e-commerce transaction," Journal of Internet Banking \& Commerce, vol. 16, no. 1, 2011.

[15] O. Rory, "An overview of the methodological approach of action research," Theory and Practice of Action Research, pp. 1-18, 2001.

[16] L. R. Baskerville and W.-H. A. Trevor, "A critical perspective on action research as a method for information systems research," Journal of Information Technology, vol. 11, no. 3, pp. 235-246, 1996.

[17] A.-S. R. Sara, "Business process modelling: Review and framework," International Journal of Production Economics, vol. 90, no. 2, pp. 129-149, 2004.

[18] G. I. Susman, “Action research: a sociotechnical systems perspective," Beyond Method: Strategies for Social Research, pp. 95113, 1983.

[19] F.-G. Fabiola, G. Houston, O. J. Elle, W.-K. Malgorzata, M. Orban and A. Melzer, "Workflow analysis, design, modeling and simulation for the multimodality imaging therapy operating system (MITOS)," 
Intraoperative Imaging and Image-Guided Therapy, pp. 325-338, Springer New York, 2014.

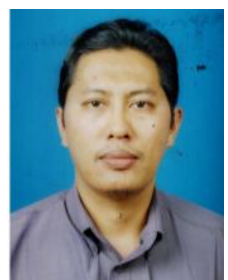

Tamrin Amboala was born in 1972 at Tawau, a small town in east cost of East Malaysia. He started his career as a tutor in Centre of External Learning in Universiti Putra Malaysia. He joined the academia way back in 2004 after obtaining his master's degree in information technology from University of Malaya, Kuala Lumpur, Malaysia, and he obtained his bachelor degree in 2002 with majoring in socio cultural and Information Technology at the same

university.

He joined the Faculty of Computing and Informatics, Labuan International Campus, University Malaysia Sabah (UMS) as a lecturer in
2005 and holding various administrative posts such as UMS Centre of External Education coordinator. He also participates in numerous conferences committee members held by the university.

$\mathrm{He}$ actively engaged in research and innovation activities after graduation and received outstanding achievement national and international level such as Bronze Medal Award (Developing Regional Fire Department Geographic Information System - Re-engineering Business Process in Fire Services), $2^{\text {nd }}$ runner up in State level in 2012 (LPG fuel Systems for motor vehicles) Bronze Medal in International Technology Exhibition in 2013 in Kuala Lumpur for the invention of heating apparatus for LPG fuel Systems.

His main research interest is business process management and business process reengineering and ICT literacy. His research work may one of its kinds to bring a technological solution to payment processing in ecommerce from Islamic Shariah perspective. He foresees and believes this research work has great potential to be explored. 